\title{
Probiotics and its Effects on Human Health-A Review
}

\author{
R. Shyamala Gowri ${ }^{*}$, P. Meenambigai ${ }^{1}$, P. Prabhavathi ${ }^{1}$, \\ P. Raja Rajeswari ${ }^{1}$ and L. Arul Yesudoss ${ }^{2}$ \\ ${ }^{1}$ Department of Microbiology and Biochemistry, NS College of Arts and Science, \\ Theni, Tamil Nadu, India- 625531 \\ ${ }^{2}$ Department of Biochemistry and Biotechnology, Sourashtra College, Tamil Nadu, India \\ *Corresponding author
}

\section{A B S T R A C T}

Keywords

Lactobacillus sp, Probiotics,

Prebiotics, Therapeutic agent.

Article Info

Accepted:

15 March 2016

Available Online:

10 April 2016
Probiotic is a live microbial food supplements with various beneficiary effects on human health. There are more evidence for the use of Probiotic as therapeutic substance for the treatment of different disorders like gastrointestinal infections, allergy, inflammatory bowel syndrome, pouchitis, Ulcerative Colitis, Crohn's disease, diarrhea, Colon cancer, etc., with dairy and non- dairy products. Probiotic not only beneficiary for humans, it is also used for animal health. This review reveals the uses of probiotics in human clinical traits.

\section{Introduction}

The intestinal track of humans is host to a vast ecology of microbes and harbors more than 500 identified species that can be cultured and many bacteria that cannot be cultured and properly identified. These bacteria which are necessary for health have the potential to contribute to the development of diseases also by a variety of mechanisms (Berg, 1996; Guarner and Malagelada, 2003). The peaceful coexistence of microbes with the host is referred to as host microbe cross-talk, implying a benefit of the microbial pressure to the host (Cebra, 1999).
Probiotics term derived from Greek word pro (favor) and bios (live). The word probiotics was introduced by Parker (1974).

\section{Origin}

The ancient records tells about the beneficial possessions of live microbial food supplements like fermented milks dates back many centuries and their usage in treatment of body ailments has been stated even in Biblical scriptures. Scientists of early ages, such as Hippocrates and others stated fermented milk not only a food product but a 
medicine as well. They recommended sour milks for treating disorders of stomach and intestines (Oberman, 1985). At the commencement of the 20th century, the Russian bacteriologist Eli Metchnikoff (Pasteur Institute, France) was the pioneer to give a scientific explanation for the benefits of lactic acid bacteria present in fermented milk (Hughes a Hoover, 1991; O'Sullivan et al., 1992). Metchnikoff described that owing to lactic acid and other yields produced by lactic acid bacteria in sour milks, the growth and toxicity of anaerobic, spore- forming bacteria in the large intestine are inhibited.

\section{Probiotics Definition}

A probiotic is defined as a feasible microbial dietetic supplement that benefits the host through its effects in the intestinal tract and this definition, however, was primarily intended for use with animal feed products. For human diet, probiotics are defined as "live microbial food supplements or components of bacteria which have beneficial effects on human health" (Salminen et al., 1998). A prebiotic is defined as "as non-absorbable food materials that beneficially arouse one or more gut-beneficial microbe groups and it have a positive effect on human health" (Gibson and Roberfroid, 1995). The most commonly used prebiotics are carbohydrate substances like dietary fiber with the capability to promote the components of the normal intestinal microflora which may exhibit a health benefit to the host. Symbiotic is the word coined for the mutual administration of precise prebiotics with probiotics to provide sure health benefits by synergistic action (Bached et al., 2004)

\section{Probiotic Organism}

Probiotics, specially Lactobacillus and Bifidobacterium have been advised to be associated with improvement of lactose intolerance (Levri et al, 2005); prevention and treatment of viral, bacterial and antibiotic or radiotherapy induced diarrheas (Guandalini, 2006; Szajewska and Mrukowicz, 2005; Parvez et al., 2006); immunomodulation (Forsythe and Bienenstock, 2010); antimutagenic (Chalova, 2008) and anticarcinogenic effects (Liong, 2008) and even blood cholesterol decrease (Ooi and Liong, 2010). The optimism related with probiotics is, however, counter-balanced by skepticism as many "probiotic" products in the market are untrustworthy in content and unproven clinically (Hughes and Hillier, 1990; Hamilton-Miller et al., 1999; Zhonget al., 1998). Many probiotic strains used for several decades for their safety and efficiency and are therefore, safe to use (Salminen et al., 1998; Adams and Marteau, 1995). Any new strain used as a probiotic should be evaluated for safety and efficacy.

\section{Organisms}

Numerous microbial species have been used as probiotics (Table 1), includes Bacillus, Bifidiobacterium, Enterococcus, Escherichia coli, Lactobacillus, Lactococcus, Streptococcus, and yeast species (Patterson and Burkholder, 2003) Lactobacillus and Bifidiobacterium species used most extensively in human.

\section{Inflammatory Bowel Disease}

Incorporation of probiotic bacteria has an ability to become stable the immunological barrier in the gut mucosa by declining the generation of local proinflammatory cytokines. Probiotics is used for treatment of the inflammatory bowel disease, such as ulcerative colitis, crohn's disease, and pouchitis. Absence of high-quality information of the causal factors, drugs that 
alleviate symptoms such as masalazine, antibiotics, corticoids, anti - diarrheal drugs and immunosuppressants have been used for action. The etiology of inflammatory bowel infections is not clear yet now and frequent factors are involved in the injury to the mucosa, including microorganisms, psychological factors and nutritional habits. Some results indicate that Inflammatory Bowel disease patients host an intestinal micro flora containing few lactobacilli (Fabia et al., 1993) and a decrease in Bifidobacteria fecal concentration. (Favier et al., 1997 and Ruseler - Van Embden et al., 1994).

\section{Pouchitis}

Pouchitis is acute or chronic inflammation of the ileal reservoir formed after colectomy and ileal pouch anal anastomosis. Ileal pouch - anal anastomosis is the preferential replacement to protocolectomy with everlasting ileostomy in ulcerative colitis and familial adenomatous poluposis. A randomized placebo - meticulous study encompassed 40 adult patients with history of chronic relapsing pouchitis who conquered clinical and endoscopic remissions with antibiotics. Patients were randomly assigned to probiotic or placebo.

After 9 months, $15 \%$ of patients getting VSL number 3 experienced a deterioration, whereas $100 \%$ of patients suffering placebo relapsed. Within 3 months of discontinuing the probiotic, all patients in the probiotic group deteriorated (Gionchetti et al., 2000).

Patients who suffered with pouchitis had a low amount of bacterial colonization and a high fungal diversity. Bacterial diversity was increased, and fungal diversity was abridged when patients were maintained in remission with VSL number 3 (Kuehbacher et al., 2006). In contrast, Lactobacillus rhamnosus
GG was not positive in a small controlled study of adult patients in pouchitis (Kuisma et al., 2003).

\section{Ulcerative Colitis}

One large randomized study of 116 patients with ulcerative colitis established that non pathogenic E.coli (Nissle, 1917) was correspondingly effectual as mesalamine in preventing relapse (Rembacken, 1999). In this study, reduction was induced with corticosteroids and patients were randomized to get hold of either probiotic or mesalamine. The median time to relapse was 206 days in mesalamine group and 221 days in the E.Coli group. However, the upkeep dose of mesalamine used in this test was little (1500 mg daily). Thus it is doubtful from this particular study whether probiotics would be more actual than low - dose mesalamine as a maintenance agent. The pouch surgery of ulcertive colitis is often complicated by a non - specific inflammation of the ileal reservoir. Bacteriotheraphy by oral intake using a mixture of probiotic bacteria has newly been revealed to be effectual in stopping relapses of chronic pouchitis (Gionchetti et al., 2000).

\section{Crohn Diseases}

Oral uptake of Lactobacillus rhamnose (GG) in patients with Crohn's disease resulted in promote of the IgA immune retort (Malin et al., 1996). A preliminary study in four children with gentle Crohn's disease recommended that L.GG may increase the gut barrier function and clinical status, but double blind placebo controlled trials have to substantiate these results.

\section{Diarrhea}

Probably the study potentially reveals 
helpful effect of probiotics is mild to sensible infectious diarrhea. Probiotics plays an imperative role in preventing nosocomial infectious diarrhea has shown challenging confirmation. A double blinded randomized control experimental using Lactobacillus GG in 81 children ages 1 to 36 months revealed a significant decrease in the menace of rotavirus gastroenteritis $(2.2 \%$ vs $6.7 \%$ ) (Szajewska et al., 2001) (NR). For a longtime, the consumption of bacteria by oral therapy in the healing of acute diarrhea (Peneet al., 1996; Caamtte, 1966; Perdigonet al., 1986).

Human isolates of Lactobacillus rhamnosus strain GG (LGG) widely used to give confidence recovery from acute rotavirus diarrhea in children. LGG when used as bacteria supplemented milk or freeze dries powder, is efficient in reduction the course of acute diarrhea.

In adult volunteers given orally with E.coli strains producing heat stable and heat labile enterotoxins, the course of the diarrhea was not improved by a marketable preparation containing dried L.acidophils and L.bulgaricus (Clements et al., 1983; Clements et al., 1981). Chronic diarrhea associated with bacterial overgrowth in adults, a crossover randomized test confirmed that a 7 day antibiotic treatment was successful in dipping daily stool frequency, whereas Saccharomyces boulardii had negative response on its parameters, atleast during this short period of treatment (Attar et al., 1999).

Acute diarrhea fallout mostly in about half of travelers who visit high risk areas. Although in most cases, acute diarrhea is meek and self-limiting, there is a widespread illness. Antibiotics are actual prophylaxis but are not recommended for widespread use and thus there is a need for cost effective another treatments. Several studies were done with the use of probiotics. Among the five double blind controlled test shows that, only one trial showed important advantage using Saccharomyces boulardii (Kollaristsch, 1993; Katelaris, 1995; Oksanen, 1990). S. boulardii seems to have very good effects on bacterial diarrhea, whereas Lactobacillus GG has to be more effective against viral and idiopathic diarrhea.

\section{Allergy}

Probiotics reduce the inflammatory cytokines and intestinal permeability in vitro such a consequence would be beneficial in allergic disorder. Several studies prove the effectiveness of probiotics in allergic conditions, such as eczema, allergic rhinitis and food allergies. The results of these studies are promising, but a definitive role is yet to be confirmed. When Lactobacillus GG or placebo was to pregnant mothers with a strong family history of eczema, allergic rhinitis asthma and to their infants for the first 6 months after delivery, the frequency of developing atopic dermatitis in the offspring was significantly reduced (Kalliomaki, 2001 and Kalliomaki, 2003).

Intestinal microorganism plays an important role in the process of food antigens in the gut and food hypersensitivity (Fig. 1), of which atopic disease is an expression. Probiotics modify the structure of antigens reduce their immunogenicity, intestinal permeability and the generation of proinflammatory cytokines that are eminent in patients with a diversity of allergic disorders. Number of studies proved that evaluated probiotics in allergic conditions including rhinitis, atopic dermatitis and food allergy.

Theories like "hygiene hypothesis" have recommended that a modern style of life could increases the development of allergic 
diseases. In most developed countries, the immune system is much less challenged as it used to be in the past by infectious diseases of different origins. The contact to infectious agents generally leads to stimulation of type 1 helper (Th1) lymphocytes and to the release of cytokines such as IFN $-\gamma$. T cells are classically classified as Th 1 , Th 2 , or Th 3 types according to their profile of cytokine secretion. Th 1 cells produce IFN - $\gamma, \mathrm{IL}-$
2 and TNF - $\beta$, which active macrophages and are responsible for cell - mediated immunity. Type and cells produce IL -4 , IL - 5, IL - 10, and IL 13, which are responsible for antibody production (IGE mainly) and eosinophil activation. Th 3 cells are regulatory cells mainly secreting suppressive cytokines such as transforming growth factor (TGF $-\beta)$.

Table.1 Most Frequently used Probiotic Microorganisms (Heyman and Ménard, 2002)

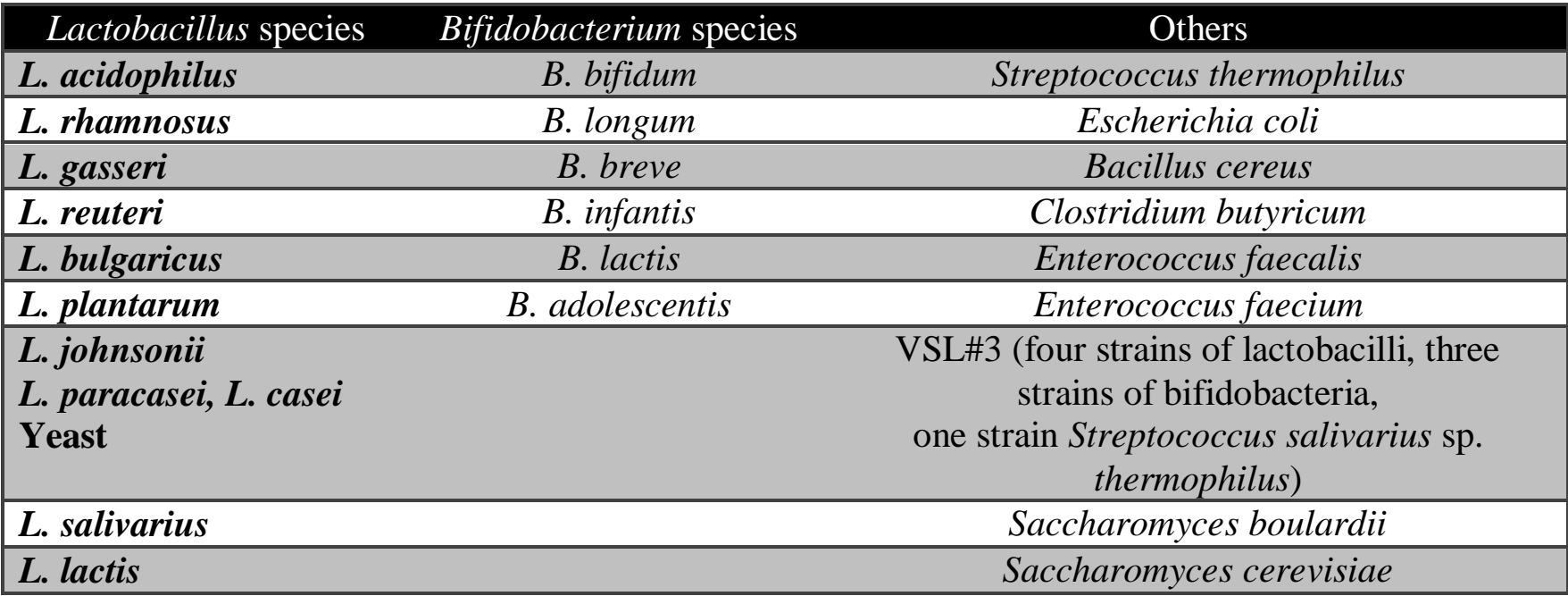

Figure.1 Commercial Bacteria Supply the Host with Essential Nutrients and Defined the Host against Opportunistic Pathogens (Marin et al., 2013)

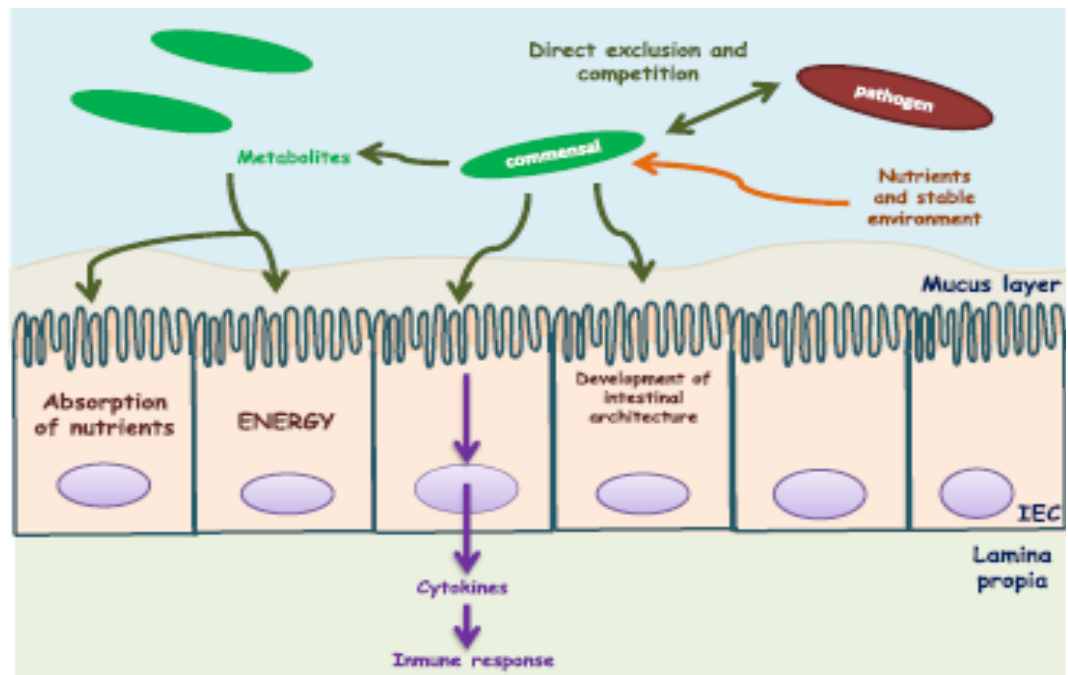




\section{Colon Cancer}

Due to somatic mutation in colon cells results in the colon cancer during the life time of an individual. Genotoxic carcinogens including heterocyclic aromatic amines, which are fashioned during the cooking of meat, are a potential risk factor of colon cancer in high - meat eaters. In vitro studies proved that the cell wall of lactic acid bacteria can adhere heterocyclic amines. Lactic acid bacteria or milk fermented products shown to exhibit anti mutagenic effects in the S. typhimurium mutagenicity assay (Renner and Munzner, 1991). In deed the link between high fat, low fiber western diets and colon cancer can be partially explained by the alterations in fecal bacterial enzymes. The mechanisms by which lactic bacteria hold back colon cancer may comprise modification of the metabolic activities of intestinal micro flora, alteration of physicochemical conditions in the colon, binding and degradation of potential carcinogens, quantitative and or qualitative alterations in the intestinal micro flora incriminated in the production of carcinogens, production of anti tumorigenic or antimutagenic compounds, enhancing the hosts immune response and effects on the physiology of the host. There is important indirect and mechanistic confirmation, based largely on laboratory animal and in vitro studies (Rafter, 2003; Rafter, 2002).

The Carcinogenic outcome of endogenous toxic and genotoxic compounds hypothetical to be inclined by the action of bacterial enzymes such as NADPH dehydrogenase, nitroreductase, $\quad \beta-$ glucosidase, $\beta-$ glucuronidase or $7-\alpha-$ dehydroxylase, which are more heavily expressed by enterobacteria, bacteroides and clostridia than by lactobacilli and Bifidobacteria. In fact such enzymes are harmful to the colon mucosa since they engage in the production of toxic compounds that have been detoxified by the liver (Hawksworth et al., 1971).

In conclusion, Probiotic are used commercially in many different products in the world. Probiotics shows various beneficial effects on humans, animal health. The organism that used as probiotic should have the characteristics like adhere ability, colonizing and balancing the gastrointestinal tract. Organisms like Lactobacillus, Bifidiobacterium, Enterobacter and E. coli are most widely used as probiotic with dairy and non- dairy products to treat various disease like gastrointestinal infections, allergy, inflammatory bowel syndrome, pouchitis, Ulcerative Colitis, Crohn's disease, diarrhea, Colon cancer.

\section{References}

Adams, M.R., Marteau, P. 1995. On the safety of lactic acid bacteria. Int. J. Food Microbiol., 27: 263-264.

Attar, A., Flourie, B., Rambaud, J.C., Franchisseur, C., Ruszniewski, P., Bouhnik, Y. 1999. Antibiotic efficacy in small intestinal bacterial overgrowth-related chronic diarrhea: a crossover, randomized trial. Gastroenterol., 117: 794-797.

Backhed, F., Ding, H., Wang, T., Hooper, L.V., Koh, G.Y., Nagy, A., et al. 2004. The gut microbiota as an environmental factor that regulates fat storage. Proc. Natl. Sci., USA, 101: 15718-23.

Berg, R.D. 1996. The indigenous gastrointestinal microflora. Trends Microbiol., 4: 430-5.

Camatte, R. 1966. Microbiologic compensation of oral antibiotherapy and treatment of acute infectious diarrhea with a new compound preparation based on lactic enzymes 
(in French). Gaz. Med. Fr., 73: 138141.

Cebra, J.J. 1999. Influences of microbiota on intestinal immune system development. Am. J. Clin. Nutr., 69: 1046-51.

Chalova, V.I., Lingbeck, J.M., Kwon, Y.M., Ricke, S.C. 2008. Extracellular antimutagenic activities of selected probiotic Bifidobacterium and Lactobacillus spp. as a function of growth phase. J. Environ. Sci. Health, 43(2): 193-8.

Clements, M.L., Levine, M.M., Black, R.E., Robins-Browne, R.M., Cisneros, L.A., Drusano, G.L., et al. 1981. Lactobacillus prophylaxis for diarrhea due to enterotoxigenic Escherichia coli. Antimicrob. Agents Chemother., 20: 104-108.

Clements, M.L., Levine, M.M., Ristaino, P.A., Daya, V.E., Hughes, T.P. 1983. Exogenous lactobacilli fed to man their fate and ability to prevent diarrheal disease. Prog. Food Nutr. Sci., 7: 29-37.

Cummings, J.H., Gibson, G.R., Macfarlane, G.T. 1989. Quantitative estimates of fermentation in the hind gut of man. Acta Vet Scand, 86: 76-82.

Fabia, R., Ar'Rajab, A., Johansson, M.L., Andersson, R., Willen, R., Jeppsson, B., et al. 1993. Impairment of bacterial flora in human ulcerative colitis and experimental colitis in the rat. Di-gestion, 54: 248-255.

Favier, C., Neut, C., Mizon, C., Cortot, A., Colombel, J.F., Mizon, J. 1997. Fecal beta-D-galactosidase production and Bifidobacteria are decreased in Crohn's disease. Dig. Dis. Sci., 42: 817-822.

Forsythe, P., Bienenstock, J. 2010. Immunomodulation by commensal and probiotic bacteria. Immunol. Invest, 39(4-5): 429-48.
Gibson, G.R., Roberfroid, M.B. 1995 Dietary modulation of the human colonic microflora: introducing the concept of prebiotics. J. Nutr., 125: 1401-12.

Gionchetti, P., Rizzello, F., Venturi, A., Brigidi, P., Matteuzzi, D., Bazzocchi, G. et al. 2000. Oral bacteriotherapy as maintenance treatment in patients with chronic pouchitis: a double-blind, placebocontrolled trial. Gastroenterol., 119: 305-309.

Gionchetti, P., Rizzello, F., Venturi, A., Brigidi, P., Matteuzzi, D., Bazzocchi, G., et al. 2000. Oral bacteriotherapy as maintenance treatment in patients with chronic pouchitis: A double-blind, placebocontrolled trial, Gastroenterol., 119: 305-309.

Guandalini, S. 2006. Probiotics for children: use in diarrhea. J. Clin. Gastroenterol., 40(3): 244-8.

Guarner, F., Malagelada, J.R. 2003. Gut flora in health and disease. Lancet, 361: 512-9.

Hamilton-Miller, J.M., Shah, S., Winkler, J.T. 1999. Public health issues arising from microbiological and labelling quality of foods and supplements containing probiotic microorganisms. Public Health Nutr., 2: 223-9.

Hawksworth, G., Drasar, B.S., Hill, M.J. 1971. Intestinal bacteria and the hydrolysis of glycosidic bonds. $J$. Med. Microbiol., 4: 451-459.

Heyman, M., Ménard, S. 2002. Probiotic microorganisms, how they affect intestinal pathophysiology. CMLS, Cell. Mol. Life Sci., 59: 001-15.

Hughes, D.B., Hoover, D.G. 1991. Bifidobacteria: Their potential for use in American dairy products. Food Technol., 45(4): 74-83. 
Hughes, V.L., Hillier, S.L. 1990. Microbiologic characteristics of Lactobacillus products used for colonization of the vagina. Obstet. Gynecol., 75: 244-8.

Isolauri, E., Juntunen, M., Rautanen, T., Sillanaukee, P., Koivula, T. 1991. A human Lactobacillus strain (Lactobacillus casei sp strain GG) promotes recovery from acute diarrhea in children. Pediatrics, 88: 90-97.

Kalliomaki, M., Salminen, S., Arvilommi, H., Kero, P., Koskinen, P., Isolauri, E. 2001. Probiotics in primary prevention of atopic disease: a randomised placebo-controlled trial. Lancet, 357: 1076-9.

Katelaris, P.H., Salam, I., Farthing, M.J. 1995. Lactobacilli to prevent traveler's diarrhea. N. Engl. J. Med., 333: $1360-1$.

Kollaritsch, H., Holst, H., Grobara, P., Wiedermann, G. 1993. Prevention of traveler's diarrhea with Saccharomyces boulardii. Results of a placebo controlled double-blind study. Fortschr Med., 111: 152-6.

Levri, K.M., Ketvertis, K., Deramo, M., Merenstein, J.H., D’Amico, F. 2005. Do probiotics reduce adult lactose intolerance. A systematic review. $J$. Fam. Pract., 54(7): 613-20.

Liong, M.T. 2008. Roles of probiotics and prebiotics in colon cancer prevention: Postulated mechanisms and in-vivo evidence. Int. J. Mol. Sci., 9(5): 854-63.

Malin, M., Suomalainen, H., Saxelin, M., Isolauri, E. 1996. Promotion of IgA immune response in patients with crohn's disease by oral bacteriotheraphy with Lactobacillus GG. Ann. Nutr. Metab., 40: 137-145.

Marin, R., Miquel, S., Ulmer, J., Kechaou, N., Langella, P., Bermudez-
Humaran, L.G. 2013. Role of commensal and probiotic bacteria in human health: a focus on inflammatory bowel disease. Microbial Cell Factories, 12: 71.

O'Sullivan, M.G., Thornton, G., O'Sullivan, G.C., Collins, J.K. 1992. Probiotic bacteria: myth or reality? Trends in Food Sci. Technol., 3: 309-314.

Oberman, H. 1985. Fermented milks. In B. J. B. Wood (Ed.), Microbiology of fermented foods. Vol. 1 (pp. 167186) London, New York, Elsevier Applied Science Publishers.

Oksanen, P.J., Salminen, S., Saxelin, M., Hamalainen, P., Ihantola- Vormisto, A., Muurasniemi-Isoviita, L., et al. 1990. Prevention of travellers' diarrhoea by Lactobacillus GG. Ann. Med., 22: 53-6.

Ooi, L.G., Liong, M.T. 2010. Cholesterollowering effects of probiotics and prebiotics: a review of in vivo and in vitro findings. Int. J. Mol. Sci., 11(6): 2499-522.

Parvez, S., Malik, K.A., Ah Kang, S., Kim, H.Y. 2006. Probiotics and their fermented food products are beneficial for health. J. App. Microbiol., 100(6): 1171-85.

Patterson, J.A., Bukholder, K.M. 2003. Application of prebiotics and probiotics in poultry production, Poultry Sci., 82: 627-631.

Pene, P., Linhard, J., Bernou, J.C. 1966. Thecolibacillus- Lactobacillus combination in the treatment of diarrhea in adults, children and infants. Sem. Hop., 42: 241-244.

Perdigon, G., Nader de Macias, M.E., Alvarez, S., Medici, M., Oliver, G., Pesce de Ruiz Holgado, A. 1986. Immunopotentiating activity of lactic bacteria administered by oral route: favorable effect in infantile diarrheas. Medicina (B. Aires), 46: 
751-754.

Rafter, J. 2002. Lactic acid bacteria and cancer: mechanistic perspective. $\mathrm{Br}$. J. Nutr., 88: S89-S94.

Rafter, J. 2003. Probiotics and colon cancer. Best Pract. Res. Clin. Gastroenterol., 17: 849-859.

Raza, S., Graham, S.M., Allen, S.J., Sultana, S., Cuevas, L., Hart, C.A. 1995. Lactobacillus GG promotes recovery from acute non bloody diarrhea in Pakistan. Pediatr. Infect. Dis. J., 14: 107-111.

Renner, H.W., Munzner, R. 1991. The possible role of probiotics as dietary antimutagen. Mutat. Res., 262: 239245.

Ruseler-van Embden, J.G., Schouten, W.R., Lieshout, L.M., van. 1994. Pouchitis: result of microbial imbalance. Gut, 35: 658-664.

Salminen, S., Bouley, C., Boutron-Ruault, M.C., Cummings, J.H., Franck, A., Gibson, G.R., et al. 1998. Functional food science and gastrointestinal physiology and function. Br. J. Nutr., 80: 147-71.

Salminen, S., von Wright, A., Morelli, L.,
Marteau, P., Brassart, D., de Vos, W.M., et al. 1998. Demonstration of safety of probiotics - a review. Int. J. Food Microbiol., 44: 93-106.

Shornikova, A.V., Isolauri, E., Burkanova, L., Lukovnikova, S., Vesikari, T. 1997. A trial in the Karelian Republic of oral rehydration and Lactobacillus GG for treatment of acute diarrhoea. Acta Paediatr, 86: 460-46.

Szajewska, H., Mrukowicz, J.Z. 2001. Probiotics in the treatment and prevention of acute infectious diarrhea in infants and children: a systematic review of published randomized, double-blind, placebocontrolled trials. J. Pediatr. Gastroenterol. Nutr., 33(2): S17.

Szajewska, H., Mrukowicz, J.Z. 2005. Use of probiotics in children with acute diarrhea. Pediatric drugs, 7(2): 11122.

Zhong, W., Millsap, K., BialkowskaHobrzanska, H., Reid, G. 1998. Differentiation of Lactobacillus species by molecular typing. Appl. Environ. Microbiol., 64: 2418-23.

\section{How to cite this article:}

Shyamala Gowri, R., P. Meenambigai, P. Prabhavathi, P. Raja Rajeswari and Arul Yesudoss, L. 2016. Probiotics and its Effects on Human Health-A Review. Int.J.Curr.Microbiol.App.Sci. 5(4): 384-392. doi: http://dx.doi.org/10.20546/ijcmas.2016.504.046 